\title{
PENGARUH KESADARAN MEREK, LOYALITAS MEREK, DAN KUALITAS YANG DAPAT DIRASAKAN UNTUK MEMPREDIKSI MINAT BELI
}

\author{
Mega Tri Novrianti Hutabarat ${ }^{1}$, Herlina Budiono ${ }^{2}$ \\ ${ }^{1}$ Program Studi Manajemen, Fakultas Ekonomi dan Bisnis, Universitas Tarumanagara \\ Email: mega.115170475@stu.untar.ac.id \\ ${ }^{2}$ Program Studi Manajemen, Fakultas Ekonomi dan Bisnis, Universitas Tarumanagara* \\ Email:herlinab@fe.untar.ac.id \\ *Penulis Korespondensi
}

\begin{abstract}
ABSTRAK
Tujuan dari penelitian ini adalah untuk menguji kesadaran merek, loyalitas merek, dan kualitas yang dapat dirasakan dapat mempengaruhi minat beli produk skincare Scarlett Whitening di Jakarta. Populasi dalam penelitian ini adalah konsumen yang membeli dan menggunakan produk perawatan kulit (skincare) Scarlett Whitening di Jakarta. Sampel pada penelitian ini sebanyak 100 responden dengan menggunakan metode non probability sampling dengan teknik convenience sampling. Teknik pengumpulan data yang dilakukan dalam penelitian ini menggunakan kuesioner yang disebarkan melalui sosial media. Software yang digunakan dalam penelitian ialah SmartPLS v.3.2.2 dan analisis dengan PLS-SEM. Hasil dari penelitian ini menghasilkan variabel kesadaran merek dan loyalitas merek memiliki pengaruh positif dan signifikan terhadap minat beli pelanggan yang membeli dan menggunakan produk perawatan kulit (skincare) Scarlett Whitening di Jakarta. Hasil dari penelitian ini juga menyatakan variabel kualitas yang dapat dirasakan memiliki pengaruh positif tetapi tidak signifikan terhadap minat beli pelanggan yang membeli dan menggunakan produk perawatan kulit (skincare) Scarlett Whitening di Jakarta.
\end{abstract}

Kata Kunci: Kesadaran Merek, Loyalitas Merek, Kualitas yang dapat dirasakan, Minat Beli

\section{ABSTRACT}

The purpose of this study was to examine brand awareness, brand loyalty, and perceived quality that could influence purchase intention in Scarlett Whitening skincare products in Jakarta. The population in this study are consumers who buy and use Scarlett Whitening skin care products in Jakarta. The sample in this study was 100 respondents using a non-probability sampling method with a convenience sampling technique. The data collection technique used in this study used a questionnaire distributed through social media. The software used in this research is SmartPLS v.3.2.2 and analysis using PLS-SEM. The results of this study indicate that the variables of brand awareness and brand loyalty have a positive and significant influence on the purchase intention of customers who buy and use Scarlett Whitening skin care products in Jakarta. The results of this study also state that the perceived quality variable has a positive but not significant effect on the purchase intention of customers who buy and use Scarlett Whitening skin care products in Jakarta.

Keywords: Brand Awareness, Brand Loyalty, Perceived Quality, Purchase Intention

\section{PENDAHULUAN}

\section{Latar Belakang}

Kementerian Perindustrian Republik Indonesia mencatat pertumbuhan pada industri kosmetik tahun 2019 sebanyak 7\% dan pada tahun 2020 meningkat menjadi 9\% dan diperkirakan akan terus meningkat hingga tahun 2022. Peningkatan yang terjadi mengakibatkan perubahan kebutuhan dan selera konsumen pada industri kecantikan yang ada di Indonesia. Dimulai dengan pada zaman dahulu perawatan kulit (skincare) hanya minyak dans yang dapat dijadikan sebagai 
salah satu bagian penting untuk menjaga kesehatan dan higienitas untuk laki-laki dan perempuan.

Fishbein dan Ajzen (1977) mengatakan Minat Beli dapat menjadi salah satu aspek penting untuk mengukur perilaku konsumen dan mengacu pada kemungkinan yang terjadi pada seorang konsumen untuk membeli suatu produk. Seorang konsumen melakukan pembelian terhadap produk perawatan kulit (skincare) biasanya melakukan pertimbangan beberapa hal seperti kebutuhan, harga, dan faktor lainnya. Kesadaran akan merek, kualitas yang dapat dirasakan dan juga loyalitas yang akan dibangun oleh merek terhadap konsumen juga dapat dijadikan faktor pertimbangan lainnya.

Kesadaran merek dapat didefinisikan bila seorang konsumen mengenali suatu merek (Aaker, 1991). Seorang konsumen mengenali suatu merek dari logo, nama, warna, dan lain-lain dapat diartikan merek tersebut menciptakan sebuah persepsi terhadap konsumen, yang dimana persepsi yang muncul dibenak konsumen memiliki pengaruh terhadap minat seorang konsumen untuk melakukan pembelian terhadap suatu produk perawatan kulit. Hal ini dapat dilihat dari seorang konsumen yang memilih untuk membeli produk perawatan kulit dari merek Scarlett Whitening.

Kualitas yang dapat dirasakan ialah sudut pandang umum pelanggan terhadap suatu produk atau layanan dan hal itu dapat mempengaruhi pilihan pelanggan dan mendorong keputusan pembelian seorang konsumen (Zeithaml, 1988; Bhuian, 1997). Pengaruh dari kualitas yang dapat dirasakan seorang konsumen untuk membuat keputusan, memilih produk Scarlett Whitening dengan alasan kualitas dari produk tersebut.

Loyalitas merek menurut Aaker (1991;1992a) ialah sebuah kecenderungan seorang beralih dari satu merek ke merek lain dan merekomendasikan untuk membeli suatu produk agar memiliki niat untuk membeli produk yang direkomendasikan. Minat beli seiring berjalannya waktu semakin meningkat dengan salah satu faktornya yaitu loyalitas merek.

Penelitian mengenai minat beli terhadap produk perawatan kulit (skincare) sudah banyak dilakukan tetapi masih minim untuk melakukan penelitian dengan produk Scarlett Whitening, perluasan jenis kelamin, umur, dan keberagaman etnis di Indonesia khususnya di Jakarta. Berdasarkan latar belakang yang telah dijelaskan dan untuk melengkapi penelitian ini, maka subjek penelitian dalam penelitian yang ini ialah pelanggan yang membeli dan menggunakan produk perawatan kulit (skincare) Scartlett Whitening di Jakarta dengan menjadikan kesadaran merek, loyalitas merek, dan kualitas yang dapat dirasakan untuk memprediksi minat beli produk Skincare Scarlett Whitening. Penelitian ini dilakukan untuk mengetahui apakah variabel yang digunakan memiliki dampak terhadap subjek yang akan diteliti.

\section{Kajian teori}

Penelitian yang dilakukan mengacu pada teori Ajzen (1991) yaitu Theory of Planned Behavior (TPB) yang dimana teori ini menjelaskan perilaku manusia melalui pendekatan dari tingkat faktor psikologis sampai faktor sosial. Theory of planned behavior Ajzen ialah hasil pengembangan dari Theory of Reasoned Action atau teori perilaku terencana (TRA). Konsep dalam teori ini mengacu pada sikap sosial, sifat kepribadian dan sikap perilaku di bawah kendali seseorang mengambil peran penting dalam memprediksi dan menjelaskan perilaku seseorang. Faktor utama Theory of Planned Behavior ialah niat seseorang untuk melakukan perilaku tertentu. Minat dapat diartikan sebagai faktor kepercayaan seseorang dengan menggunakan informasi yang dimiliki, dimana hal ini dapat memprediksi perilaku seseorang. 
Minat Beli menurut Fishbein dan Ajzen (1977) ialah salah satu aspek penting untuk mengukur perilaku konsumen dan mengacu pada kemungkinan yang terjadi pada seorang konsumen untuk membeli suatu produk. Minat beli juga dapat digunakan sebagai minat seorang konsumen membeli sebuah produk dan jika hubungan antara kedua komponen tersebut semakin besar maka semakin besar juga minat beli seorang konsumen terhadap sebuah produk (Dodds, 1991). Menurut Hendri dan Budiono (2021) dalam penelitiannya minat beli diartikan sebagai keinginan atau rencana konsumen untuk membeli sebuah produk atau merek.

Kesadaran merek menurut Aaker (1991) menjelaskan dimana seorang konsumen dapat mengenali sebuah merek dan hal tersebut juga dapat dianggap sebagai penciptaan nilai bagi seorang konsumen. Pernyataan tersebut juga didukung oleh pernyataan menurut Kim \& Kim (2015) bahwa kesadaran merek dapat dikaitkan dengan kekuatan sebuah merek dibenak seorang konsumen.

Kualitas yang dapat dirasakan menurut Zeithaml (1988) ialah sudut pandang umum pelanggan terhadap suatu produk atau layanan dan hal itu dapat mempengaruhi pilihan pelanggan dan mendorong keputusan pembelian seorang konsumen. Pernyataan tersebut didukung oleh Aaker (1991) bahwa kualitas yang dapat dirasakan dapat mempengaruhi keputusan pembelian seorang konsumen.

Loyalitas Merek menurut Yoo et al. (2000) merupakan mempunyai kemampuan membuat seorang konsumen dipengaruhi pilihannya dalam memilih suatu merek dan tidak beralih ke merek lain. Dalam penelitian Fenetta, A., \& Keni. (2019) loyalitas merek dinyatakan sebagai sebuah perasaan bersifat positif untuk menunjukkan sebuah komitmen seorang konsumen terhadap sebuah merek dan melakukan pembelian secara berulang.

Berdasarkan kajian teori yang ada, maka model penelitiannya dapat dirumuskan sebagai berikut:

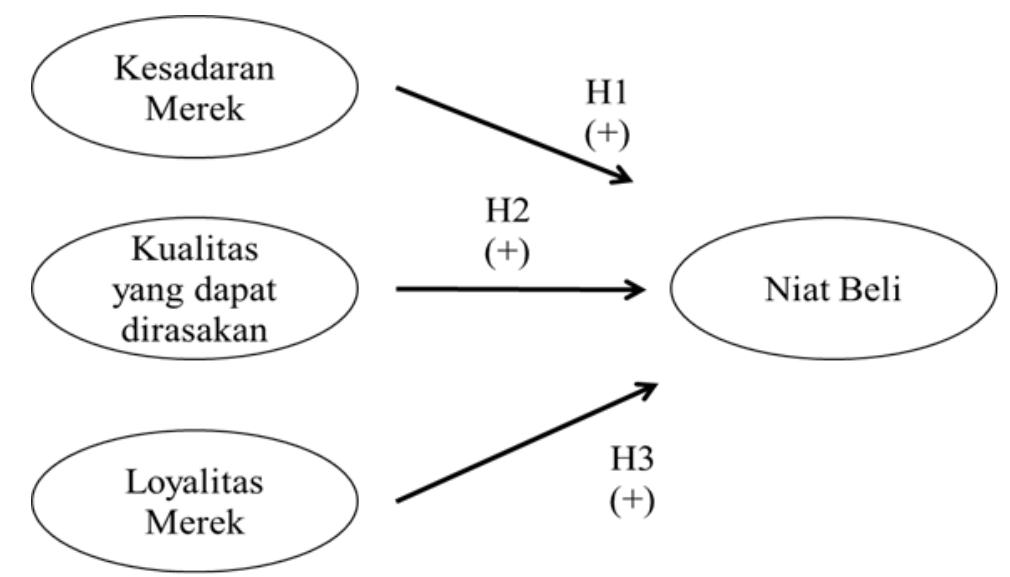

Gambar 1. Model penelitian

Berdasarkan model penelitian di atas maka hipotesis dalam penelitian ini sebagai berikut:

H1: Kesadaran Merek memiliki pengaruh yang positif terhadap Minat Beli pada konsumen produk Scarlett Whitening di Jakarta.

$\mathrm{H} 2$ : Kualitas yang dapat dirasakan memiliki pengaruh yang positif terhadap Minat Beli pada konsumen produk Scarlett Whitening di Jakarta.

H3: Loyalitas Merek memiliki pengaruh yang positif terhadap Minat Beli pada konsumen produk Scarlett Whitening di Jakarta. 


\section{METODE PENELITIAN}

Hasil penelitian ini didapatkan melalui penyebaran kuesioner kepada pelanggan yang membeli dan menggunakan produk perawatan kulit (skincare) Scarlett Whitening di Jakarta. Desain penelitian ini menggunakan desain penelitian deskriptif yang bertujuan untuk dapat mendeskripsikan suatu peristiwa atau kejadian (Sarwono, J. \& Budiono, 2012:1). Teknik pengambilan sampel yang dilakukan penelitian ini ialah non-probability sampling dengan teknik convenience sampling yang dimana hanya beberapa dari populasi yang bisa menjadi sampel. Skala yang digunakan dalam penelitian ini ialah skala Likert dan menyatakan skala Likert sendiri dirancang untuk dapat menguji seberapa besar dan kuat seorang responden terhadap pernyataan yang ada menurut Sekaran dan Bougie (2013). Variabel yang diteliti dalam penelitian ini ialah kesadaran merek, loyalitas merek, kualitas yang dapat dirasakan sebagai independen dan minat beli sebagai variabel dependen.

\section{HASIL DAN PEMBAHASAN}

Responden yang didapatkan dalam penelitian ini berjumlah 100 orang yang mengisi kuesioner yang disebarkan secara online melalui media sosial. Berdasarkan data yang didapatkan, dapat dilihat bahwa jumlah responden berjenis kelamin perempuan sebanyak 89 orang (89\%) dan jumlah responden berjenis laki - laki sebanyak 11 orang $(11 \%)$ dari total responden yang berjumlah 100 orang. Karakteristik responden dalam penelitian ini dilihat dari usia, yang dimana dibagi menjadi 4 (empat) kategori dibawah 17 tahun, 17-19 tahun, 20-22 tahun, 23-25 tahun dan diatas 25 tahun. Berdasarkan data yang didapatkan dalam penyebaran kuesioner ini bahwa jumlah responden dengan rentang usia dibawah 17-19 tahun sebanyak 16 orang (16\%), kemudian jumlah responden dengan rentang usia 20-22 tahun sebanyak 75 orang (75\%), jumlah responden dengan rentang usia 23 - 25 tahun sebanyak 7 orang $(7 \%)$ dan jumlah responden dengan diatas 25 tahun sebanyak 2 orang (2\%) dari total responden yang berjumlah 100 orang. Karakteristik responden juga dibagi berdasarkan wilayah di Jakarta yang dibagi menjadi 5 (lima) yaitu Jakarta Barat, Jakarta Selatan, Jakarta Utara, Jakarta Pusat dan Jakarta Timur. Berdasarkan data yang didapatkan bahwa responden yang berdomisili Jakarta Barat sebanyak 48 orang (48\%). Jumlah responden yang berdomisili di Jakarta Selatan sebanyak 7 orang (7\%). Jumlah responden yang berdomisili di Jakarta Utara sebanyak 13 orang (13\%), jumlah responden yang berdomisili di Jakarta Timur 25 orang (25\%) dan jumlah responden berdomisili di Jakarta Pusat 7 orang $(7 \%)$.

\section{Hasil Uji Validitas}

Validitas merupakan pengujian mengenai seberapa baik suatu instrumen pengukuran dalam mengukur apa yang seharusnya diukur (Sekaran \& Bougie, 2013). Analisis validitas dengan menggunakan teknik structural equation model (SEM) terbagi menjadi validitas konvergen dan validitas diskriminan.

Tabel 1. Hasil Nilai Average Variance Extracted (AVE)

Sumber: Pengolahan data SmartPLS 3.0

\begin{tabular}{|c|c|}
\hline Variabel & Average Variance Extracted \\
\hline Kesadaran Merek & 0,659 \\
\hline Kualitas yang dapat dirasakan & 0,777 \\
\hline Loyalitas Merek & 0,760 \\
\hline Minat Beli & 0,732 \\
\hline
\end{tabular}

Menurut Hair et al. (2011) validitas konvergen akan dianggap valid bila nilai AVE (average variance extracted) lebih dari 0,50 (>0,50). Hasil dari analisis Average Variance Extracted pada menunjukkan bahwa setiap variabel memiliki nilai lebih dari $0,50(>0,50)$. Uji reliabilitas 
indikator dinilai berdasarkan loading factor pada indikator yang mengukur konstruk tersebut. Hair et al. (2019) menyatakan bahwa loading factor yang dimiliki setiap indikator bernilai 0,6 hingga 0,70 masih dapat diterima.

Tabel 2. Hasil nilai Loading factor

Sumber: Pengolahan Data SmartPLS 3.0

\begin{tabular}{|c|c|c|}
\hline \multicolumn{2}{|r|}{ Indikator } & Loading factor \\
\hline BA 2 & $\begin{array}{l}\text { Dapat mengenali produk perawatan kulit (skincare) Scarlett Whitening secara } \\
\text { mudah }\end{array}$ & 0,751 \\
\hline BA 3 & $\begin{array}{l}\text { Beberapa karakteristik produk perawatan kulit (skincare) Scarlett Whitening } \\
\text { dapat langsung muncul di benak konsumen secara spontan }\end{array}$ & 0,850 \\
\hline BA 4 & $\begin{array}{l}\text { Dapat dengan cepat mengingat simbol atau logo produk perawatan kulit } \\
\text { (skincare) Scarlett Whitening }\end{array}$ & 0,753 \\
\hline BA 5 & $\begin{array}{l}\text { Produk perawatan kulit (skincare) Scarlett Whitening mudah diingat merek } \\
\text { produknya }\end{array}$ & 0,885 \\
\hline PQ 1 & Produk perawatan kulit (skincare) Scarlett Whitening berkualitas tinggi & 0,856 \\
\hline PQ 2 & $\begin{array}{l}\text { Produk perawatan kulit (skincare) Scarlett Whitening memberikan hasil yang } \\
\text { sesuai }\end{array}$ & 0,910 \\
\hline PQ 3 & $\begin{array}{lrllll}\begin{array}{l}\text { Produk } \\
\text { diandalkan/dipercaya }\end{array} & \text { perawatan } & \text { (skincare) } & \text { Scarlett } & \text { Whitening } & \text { dapat } \\
\end{array}$ & 0,900 \\
\hline PQ 4 & $\begin{array}{l}\text { Secara keseluruhan, produk perawatan kulit (skincare) Scarlett Whitening } \\
\text { menawarkan kualitas dengan lebih baik dari yang ditawarkan oleh produk } \\
\text { perawatan kulit lain }\end{array}$ & 0,841 \\
\hline PQ 5 & Produk perawatan kulit (skincare) dapat dipercaya kualitasnya & 0,900 \\
\hline BL 1 & $\begin{array}{l}\text { Besar keinginan membeli produk perawatan kulit (skincare) Scarlett } \\
\text { Whitening lagi }\end{array}$ & 0,896 \\
\hline BL 2 & $\begin{array}{l}\text { Produk perawatan kulit (skincare) Scarlett Whitening akan menjadi pilihan } \\
\text { utama, bila terdapat produk perawatan kulit lain di toko }\end{array}$ & 0,882 \\
\hline BL 3 & $\begin{array}{l}\text { Dibandingkan dengan produk perawatan kulit lain, produk perawatan kulit } \\
\text { Scarlett Whitening lebih disukai }\end{array}$ & 0,898 \\
\hline BL 4 & $\begin{array}{l}\text { Produk perawatan kulit (skincare) Scarlett Whitening banyak disarankan pada } \\
\text { konsumen lain }\end{array}$ & 0,847 \\
\hline BL 5 & $\begin{array}{l}\text { Produk perawatan kulit (skincare) Scarlett Whitening akan menjadi pilihan } \\
\text { pertama }\end{array}$ & 0,835 \\
\hline PI 1 & $\begin{array}{l}\text { Memiliki kemungkinan untuk membeli produk perawatan kulit (skincare) } \\
\text { Scarlett Whitening }\end{array}$ & 0,861 \\
\hline PI 3 & $\begin{array}{l}\text { Produk perawatan kulit (skincare) Scarlett Whitening dapat dibeli karena } \\
\text { melihat di media sosial }\end{array}$ & 0,799 \\
\hline PI 5 & $\begin{array}{l}\text { Memiliki kemungkinan mencoba beli produk dari produk perawatan kulit } \\
\text { (skincare) Scarlett Whitening }\end{array}$ & 0,904 \\
\hline
\end{tabular}

Berdasarkan hasil dari Tabel 2, telah menunjukkan bahwa seluruh indikator memiliki nilai loading factor di atas 0,60 $(>0,60)$ hal ini dapat disimpulkan bahwa data penelitian ini reliabel dan valid karena memenuhi kriteria yang ada.

Tabel 3. Hasil Pengujian Reliabilitas

Sumber: Pengolahan Data SmartPLS 3.0

\begin{tabular}{|l|c|c|}
\hline \multicolumn{1}{|c|}{ Variabel } & Cronbach's Alpha & Composite Reliability \\
\hline Kesadaran Merek & 0,827 & 0,885 \\
\hline Kualitas yang dapat dirasakan & 0,928 & 0,946 \\
\hline Loyalitas Merek & 0,921 & 0,941 \\
\hline Minat Beli & 0,816 & 0,891 \\
\hline
\end{tabular}

Uji reliabilitas konsistensi internal dapat dilihat di tabel 3 dari nilai composite reliability dan cronbach's alpha yang digunakan untuk mengukur nilai reliabilitas dari suatu konstruk. Menurut 
Hair et al. (2019) indikator dapat dikatakan valid atau diterima apabila lebih dari $0,7(>0,7)$, meskipun nilai 0,6 masih dapat diterima.

\section{Hasil Uji Adjust R-Square $\left(\mathbf{R}^{2}\right)$}

Tabel 4. Hasil Uji Adjust R-Square $\left(\mathrm{R}^{2}\right)$

Sumber: Pengolahan Data SmartPLS 3.0

\begin{tabular}{|c|c|}
\hline Variabel & R-Square \\
\hline Minat Beli & 0,657 \\
\hline
\end{tabular}

Berdasarkan hasil analisis R-Square pada tabel 4, terdapat nilai R-Square sebesar 0,657 yang menjelaskan bahwa sebesar $65,7 \%$ dari variabel kesadaran merek, kualitas yang dapat dirasakan, loyalitas merek dan minat beli. Sisanya $34,3 \%$ dapat dijelaskan oleh variabel yang tidak diteliti dalam penelitian ini dan variabel lainnya.

\section{Hasil Uji Q-Square $\left(Q^{2}\right)$}

Tabel 5. Hasil Uji Q-Square $\left(\mathrm{Q}^{2}\right)$

Sumber: Pengolahan Data SmartPLS 3.0

\begin{tabular}{|c|c|}
\hline Variabel & $\mathbf{Q}^{2}$ \\
\hline Minat Beli & 0.440 \\
\hline
\end{tabular}

Predictive relevance atau biasa disebut $Q$-Square dikatakan baik apabila memiliki nilai lebih besar daripada 0 (>0) (Hair et al., 2011). Pada hasil analisis predictive relevance $\left(\mathrm{Q}^{2}\right)$ pada tabel 4.12 menjelaskan bahwa hubungan konstruk variabel-variabel yang diteliti dalam penelitian ini dianggap relevan dengan baik, karena memiliki $\left(\mathrm{Q}^{2}\right)$ yang $>0$ (lebih besar dari 0 ).

\section{Hasil Uji $F$-Square $\left(\mathbf{F}^{2}\right)$}

Tabel 6. Hasil Uji F-Square $\left(\mathrm{F}^{2}\right)$

Sumber: Pengolahan Data SmartPLS 3.0

\begin{tabular}{|l|c|}
\hline \multicolumn{1}{|c|}{ Variabel } & F-Square \\
\hline Kesadaran Merek terhadap Minat Beli & 0,134 \\
\hline Kualitas yang dapat dirasakan terhadap Minat Beli & 0,018 \\
\hline Loyalitas Merek terhadap Minat Beli & 0,418 \\
\hline
\end{tabular}

Berdasarkan pada tabel 6, nilai F-Square 0,134 dan 0,018 memiliki hubungan yang lemah. Sedangkan nilai F-Square 0,418 memiliki hubungan yang kuat.

\section{Hasil Uji Hipotesis (Path Coefficient)}

Tabel 7. Hasil Uji Hipotesis (Path Coefficient)

Sumber: Pengolahan data SmartPLS 3.0

\begin{tabular}{|l|c|c|c|}
\hline \multicolumn{1}{|c|}{ Variabel } & Path Coefficient & t-statistics & p-values \\
\hline Kesadaran Merek -> Minat Beli & 0,230 & 2,082 & 0,019 \\
\hline Kualitas yang dapat dirasakan -> Minat Beli & 0,600 & 1,296 & 0,098 \\
\hline Loyalitas Merek -> Minat Beli & 0,122 & 5,949 & 0,000 \\
\hline
\end{tabular}

Berdasarkan pada Tabel 7, dapat disimpulkan bahwa hipotesis H1 dan H3 tidak ditolak artinya memiliki pengaruh positif dan signifikan. Sedangkan $\mathrm{H} 2$ tidak ditolak, memiliki pengaruh positif tetapi tidak signifikan. 


\section{Diskusi}

Hasil pengujian hipotesis variabel kesadaran merek terhadap minat beli, memiliki nilai $t$ statistics sebesar 2,082 dan nilai p-values 0,019 sehingga dapat disimpulkan bahwa kesadaran merek memiliki pengaruh positif dan signifikan terhadap minat beli produk perawatan kulit (skincare) Scarlett Whitening di Jakarta. Hasil dari penelitian ini sejalan dengan penelitian terdahulu yang menjelaskan bahwa kesadaran merek memiliki pengaruh positif dan signifikan terhadap minat beli.

Hasil pengujian hipotesis variabel kualitas yang dapat dirasakan terhadap minat beli, memiliki nilai $t$-statistics sebesar 1,296 dan nilai p-values 0,098 sehingga dapat disimpulkan bahwa kualitas yang dapat dirasakan memiliki pengaruh positif tetapi tidak secara signifikan terhadap minat beli produk perawatan kulit (skincare) Scarlett Whitening di Jakarta. Hasil dari penelitian ini sejalan dengan penelitian yang sudah pernah dijalankan dan menjelaskan bahwa kualitas yang dapat dirasakan memiliki pengaruh positif terhadap minat beli.

Hasil pengujian hipotesis variabel loyalitas merek terhadap minat beli, memiliki nilai $t$-statistics sebesar 5,949 dan nilai p-values 0,000 sehingga dapat disimpulkan bahwa loyalitas merek memiliki pengaruh positif dan signifikan terhadap minat beli produk perawatan kulit (skincare) Scarlett Whitening di Jakarta. Hasil dari penelitian ini didukung dengan penelitian terdahulu yang menyatakan bahwa loyalitas merek memiliki pengaruh positif dan signifikan terhadap minat beli.

\section{KESIMPULAN DAN SARAN}

Berdasarkan hasil penelitian dari pengujian data dalam penelitian ini menunjukkan bahwa kesadaran merek, kualitas yang dapat dirasakan, dan loyalitas merek mempunyai hubungan yang positif tetapi untuk variabel kualitas yang dapat dirasakan terhadap minat beli tidak signifikan. Hal ini dapat terjadi karena kesadaran merek, kualitas yang dapat dirasakan, dan loyalitas merek merupakan komponen yang penting dan dapat mempengaruhi minat beli produk perawatan kulit (skincare) Scarlett Whitening di Jakarta.

Berdasarkan hasil penelitian ini, maka beberapa saran yang dapat diberikan oleh peneliti ialah sebegai berikut: (1) Peneliti menyarankan kesadaran merek yang dibangun oleh produk Scarlett Whitening dapat dipertahankan dan ditingkatkan agar konsumen yang membeli dan menggunakan produk Scarlett Whitening dapat diingat dalam benak konsumen dan juga membantu meningkatkan pembelian produk yang ada. (2) Peneliti menyarankan kualitas yang dapat dirasakan dari produk Scarlett Whitening dapat dipertahankan dalam jangka panjang agar penilaian yang sudah tercipta dibenak konsumen yang membeli dan menggunakan produk Scarlett Whitening dapat tetap stabil dan kualitas yang dapat dirasakan juga dapat mempengaruhi pembelian. (3) Peneliti menyarankan loyalitas merek dari produk Scarlett Whitening yang sudah tercipta dapat terus terjaga dan dapat meningkatkan kesetiaan seorang konsumen terhadap merek Scarlett Whitening itu sendiri. (4) Bagi penelitian selanjutnya dapat menambahkan variabel yang mempengaruhi minat beli antara lain seperti Electronic Word of Mouth, pengetahuan tentang produk, asosiasi merek dan variabel lainnya, dan menambahkan jumlah sampel dan populasi. Hal ini dilakukan agar dapat menghasilkan data yang lebih bervariasi dan baik. (5) Penyebaran kuesioner dapat dilakukan tidak hanya konsumen yang membeli dan menggunakan produk perawatan kulit (skincare) Scarlett Whitening di Jakarta melainkan di daerah lainnya. (6) Hasil penelitian ini diharapkan dapat menjadi referensi untuk penelitian selanjutnya dalam menjelaskan kesadaran merek, kualitas yang dapat dirasakan, dan loyalitas merek terhadap minat beli. 


\section{REFERENSI}

Aaker, D. A. (1991). Managing Brand Equity. Capitalizing on the Value of Brand Name. The Free Press, 28(1), 35-37.

Bhuian, S. N. (1997). Marketing cues and perceived quality: Perceptions of Saudi consumers toward products of the U.S., Japan, Germany, Italy, U.K. and France. Journal of Quality Management, 2(2), 217-234. https://doi.org/10.1016/S1084-8568(97)90004-3

Chaudhuri, A., \& Holbrook, M. B. (2001). The Chain of Effects from Brand Trust and Brand Affect to Brand Performance: The Role of Brand Loyalty. Journal of Marketing, 65(2), 81-93. https://doi.org/10.1509/jmkg.65.2.81.18255

Dodds, W. B., Monroe, K. B., \& Grewal, D. (1991). Effects of Price, Brand, and Store Information on Buyers' Product Evaluations. Journal of Marketing Research, 28(3), 307319. https://doi.org/10.1177/002224379102800305

Fenetta, A., \& Keni. (2019). Pengaruh Brand Awareness dan Perceived Quality terhadap Purchase Intention: Brand Loyalty sebagai variabel mediasi. Jurnal Manajemen dan Kewirausahaan, 4(6), 270-275. https://doi.org/10.24912/jmbk.v4i6.9792

Fishbein, M., \& Ajzen, I. (1977). Belief, attitude, intention, and behavior: an introduction to theory and research. Journal of Business Venturing, 5, 177-189.

Hair, J. F., Risher, J. J., Sarstedt, M., \& Ringle, C. M. (2019). When to use and how to report the results of PLS-SEM. European Business Review, 31(1), 2-24.

https://doi.org/10.1108/EBR-11-2018-0203

, Sarstedt, M., Hopkins, L., \& Kuppelwieser, V. G. (2014). Partial least squares structural equation modeling (PLS-SEM): An emerging tool in business research. European Business Review, 26(2), 106-121.

https://doi.org/10.1108/EBR-10-2013-0128

Hendri \& Budiono, H.. (2021). Pengaruh Brand Image, Brand Trust, EWOM terhadap Purchase Intention pada produk H\&M pada masa pandemi Covid-19. Jurnal Manajerial dan Kewirausahaan, 3(2), 371-379.

https://doi.org/10.1177/002224298805200302

Jonathan, S., \& Budiono, Herlina. (2012).Statistik Terapan:Aplikasi Untuk Riset Skripsi, Tesis dan Disertasi (Menggunakan SPSS, AMOS, dan Excel). Jakarta: PT Elex Media Komputindo, Gramedia.

Khan, N., R Rahman, S. H., Hoe, H. Y., \& Chen, T. B. (2014). Causal Relationships among Dimensions of Consumer-Based Brand Equity and Purchase Intention: Fashion Industry. International Journal of Business and Management, 10(1), 172. http://dx.doi.org/10.5539/ijbm.v10n1p172

Kim, H. B., \& Kim, W. G. (2005). The relationship between brand equity and firms' performance in luxury hotels and chain restaurants. Tourism Management, 26(4), 549560. https://doi.org/10.1016/j.tourman.2004.03.010

Sekaran, U., \& Boogie, R. (2013). Research Methods for Business: A Skill-Building Approach (6th ed.). Wiley.

Zeithaml, V. A. (1988). Consumer perceptions of price, quality, and value: a means-end model and synthesis of evidence. Journal of Marketing, 52(3), 2-22. 